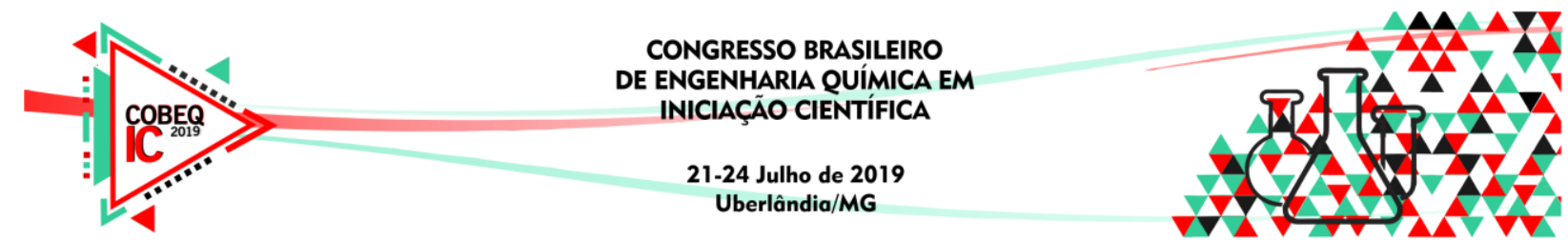

\title{
MATERIAIS BIODEGRADÁVEIS DE FÉCULA DE MANDIOCA REFORÇADOS COM NANOPARTÍCULAS DE ARGILA E NANOFIBRAS DE CELULOSE
}

\author{
A.C. SOUZA ${ }^{1}$ e F. L. M. OLIVEIRA ${ }^{1}$ \\ ${ }^{1}$ Universidade Federal do Triângulo Mineiro (UFTM) Programa de Pós-Graduação \\ Interdisciplinar em Biociências Aplicadas (PIBA) \\ E-mail para contato: luizafemendonca@gmail.com
}

\begin{abstract}
RESUMO - A proposta deste trabalho foi analisar o efeito da incorporação de nanopartículas de argila e nanofibras de celulose como reforço estrutural dos materiais biodegradáveis de fécula de mandioca, visando a melhora de suas propriedades para aplicação em embalagens de alimentos em substituição aos polímeros derivados do petróleo. Todos os materiais confeccionados foram caracterizados em relação às suas propriedades mecânicas (resistência à tração e elongação na ruptura), de barreira (permeabilidade ao vapor de água) e morfológicas (teor de umidade, solubilidade e grau de intumescimento). Os materiais apresentaram boa aparência, com superfície homogênea com média de espessura de $90 \mu \mathrm{m}$, os reforços diminuíram as propriedades de barreira e contribuíram para a diminuição da umidade, porém não modificaram solubilidade e grau de intumescimento dos filmes conforme esperado.
\end{abstract}

\section{INTRODUÇÃO}

Com a velocidade do mundo moderno e a necessidade de praticidade no dia a dia, as embalagens plásticas são bastantes utilizadas, pois protegem os alimentos e são fáceis de manusear. Segundo a Associação Brasileira de Embalagens (ABRE), os materiais poliméricos usados para embalagens plásticas apresentam vantagens como baixo peso, baixo custo e elevada resistência mecânica e química, por isso sua versatilidade. Por outro lado, sabe-se que são responsáveis por muitos problemas ambientais, devido ao seu descarte inadequado.

Causando danos ao meio ambiente, acumuladas em aterros, descartadas nas ruas e entupindo bueiros, prejudicando os animais do ambiente marinho, entre outros. Dessa maneira, o estudo de embalagens biodegradáveis é frequente e relevante, uma vez que possuem características semelhantes aos plásticos, entretanto degradam com mais facilidade quando em contato com os microrganismos.

O amido é de bastante interesse na formação dessas embalagens devido à sua abundância em diversas fontes vegetais, portanto acabam apresentando baixo custo, além de apresentar elevada biodegrabilidade (Henrique et al., 2008). Uma de suas fontes que pode ser utilizada como matriz dos filmes é a fécula de mandioca (Souza, 2011), que apresenta escolha justificada, por ser bastante produzida no país, uma vez que o Brasil em 2017 produziu cerca de 2.763.000 toneladas de acordo com dados do IBGE. 


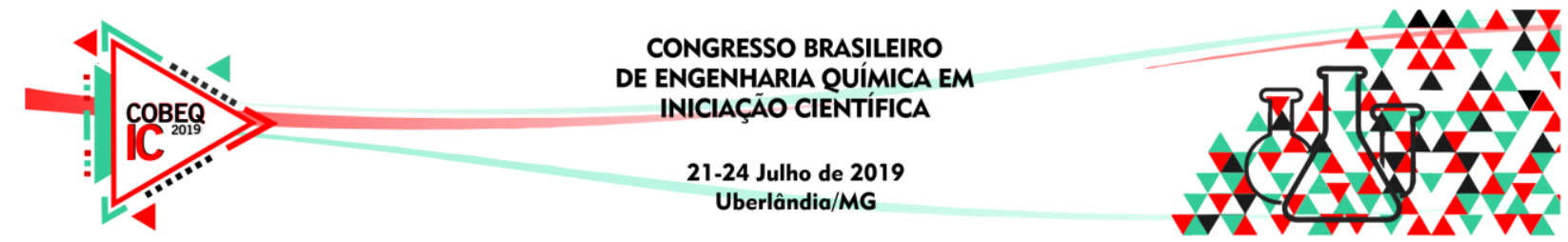

Apesar de os filmes a base de fécula de mandioca apresentarem importância no cenário da pesquisa vale ressaltar que apresentam propriedades mecânicas e de barreira pobres em relação aos polímeros sintéticos derivados de petróleo, justificante a necessidade de estudos sobre reforços que melhorem suas características (Machado, 2011). Dessa forma, foram analisados neste trabalho a incorporação de nanofibras de celulose e nanopartículas de argila, como reforços, na tentativa de melhorar as propriedades dos materiais poliméricos biodegradáveis a base de fécula de mandioca.

\section{METODOLOGIA}

\subsection{Elaboração dos filmes}

Todos os filmes estudados foram elaborados por casting, consistindo na formação de uma solução filmogênica pela mistura homogênea dos componentes, sob aquecimento constante até aproximadamente $72^{\circ} \mathrm{C}$ e agitação manual, seguida por espalhamento sobre suportes ( placas de polipropileno com $14 \mathrm{~cm}$ de diâmetro) e secagem em capela de fluxo laminar por $24 \mathrm{~h}$. Para $100 \mathrm{~g}$ de formulação filmogênica, utilizou-se $5,0 \mathrm{~g}$ de fécula de mandioca (Cargill Agrícola S. A.), 0,75g de glicerol (Synth) e 95g de água destilada. Foram elaborados filmes sem reforços mecânicos (FM); filmes reforçados com 0,05 g, 0,10 g e 0,15 g de nanopartículas de argila (denominados A1, A2 e A3) (Argel T, Bentonit União); e filmes reforçados com 0,2 g, 0,3 g e 0,4 g de nanofibras de celulose (denominados C1, C2, C3) (Suzano Papel e Celulose®).

Antes de realizar os ensaios de caracterização, os filmes foram acondicionados em ambiente controlado com solução saturada de cloreto de sódio, o qual fornece uma umidade relativa de $75 \%$, por no mínimo $48 \mathrm{~h}$, à temperatura ambiente.

\subsection{Caracterizações dos filmes}

A primeira caracterização a ser realizada foi em relação ao aspecto visual dos materiais, sendo o ideal que os filmes apresentem boa aparência, sem fissuras, poucas ou nenhuma bolhas. Os filmes não considerados ideais foram descartados. A espessura $(e)$ dos filmes foi determinada por um micrômetro de ponta planar (OUTSIDE MICROMETER, 0-25 $\mathrm{mm})$, em posições aleatórias. A opacidade $(O)$ e a transparência $(T)$ foram determinadas de acordo com a passagem de luz pelos filmes, em um espectrofotômetro (Ultrospec 8000) a 600 nm (Marques, 2018), e quantificadas pelas Equações 1 e 2, sendo $A b s$ a absorbância fornecida pelo equipamento.

$$
\begin{aligned}
& O=\frac{-\log (A b s)}{e} \\
& T=\frac{A b s}{e}
\end{aligned}
$$

O teor de umidade em base úmida dos filmes $(U)$ foi determinado pela Equação 3, colocando amostras quadradas de $20 \mathrm{~mm}$ com massa inicial (mi) quantificada em estufa, a $105^{\circ} \mathrm{C}$, sendo a massa final $(m f)$ aferida após $24 \mathrm{~h}$. 


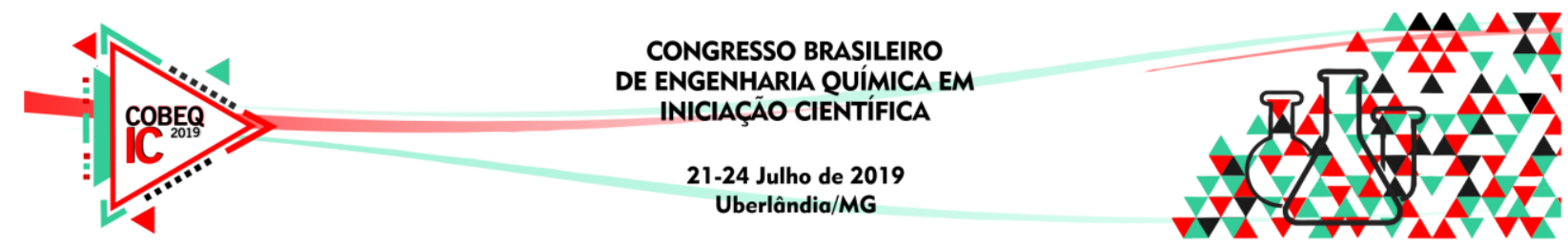

$$
U=\frac{(m f-m i)}{m i} \times 100
$$

Para determinar a solubilidade em água dos filmes $(S)$, conforme Equação 4, amostras quadradas de $20 \mathrm{~mm}$ com massa inicial (mi) quantificada, ficaram $24 \mathrm{~h}$ imersas em água, sob leve agitação, em seguida foram levadas à secagem em estufa a $105{ }^{\circ} \mathrm{C}$, até apresentarem massa constante, que corresponde à massa final $(m f)$.

$$
S=\frac{m i \times(1-0,01 * U)-m f}{m i \times(1-0,01 * U)} \times 100
$$

Para determinar o grau de intumescimento $(G I)$ dos filmes, conforme Equação 5, amostras quadradas de $20 \mathrm{~mm}$ com massa inicial $(\mathrm{mi})$ quantificada foram imersas em água destilada, sob leve agitação, sendo a massa úmida aferida em períodos de tempo até valor constante, correspondente à massa final $(m f)$.

$$
G I=\frac{m f-m i}{m i}
$$

A permeabilidade ao vapor de água $(P V A)$, foi determinada pelo procedimento graviométrico de acordo com o método da American Society for Testing and Materials ASTM E 96/E 96M-05 (2005), com modificações. Os testes foram realizados a temperatura ambiente, em triplicata.

Todas as análise foram realizadas em triplicata e os resultados tratados estatisticamente usando o programa GraphPad Prisma, considerando o erro puro. O teste de Tukey foi aplicado para análise das diferenças significativas entre os resultados obtidos, no intervalo de confiança de $95 \%$.

\section{RESULTADOS E DISCUSSÕES}

Com a Figura 1, é possível ver a boa aparência dos filmes, sem bolhas e fissuras, homogêneos em toda superfície, com espessura média de $90 \mu \mathrm{m}$.

gura 1 - Fotografias de materiais biodegradáveis a base de fécula de mandioca (FM), reforçados com nanopartículas de argila (A1, A2, A3) e nanofibras de celulose $(\mathrm{C} 1, \mathrm{C} 2, \mathrm{C} 3)$.

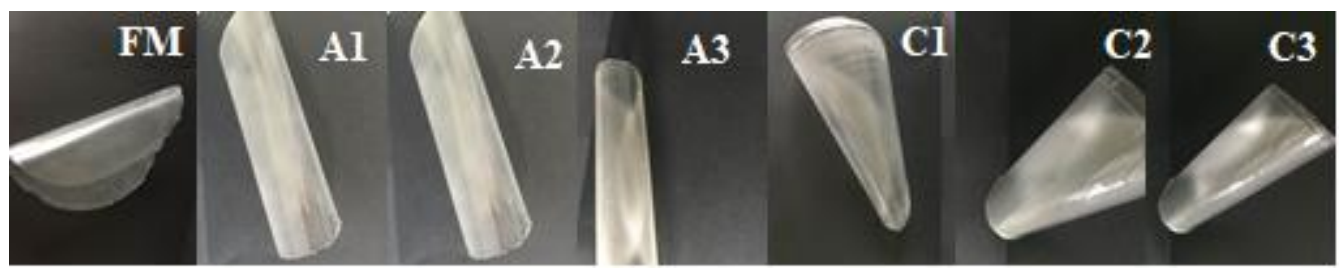

Tanto a opacidade quanto a transparência das embalagens são importantes para a apresentação visual do produto final embalado, uma vez que estas propriedades indicam a quantidade de luz que atravessa a superfície analisada, sendo a opacidade uma grandeza inversamente proporcional à passagem de luz e a transparência diretamente proporcional (Marques, 2018). Ou seja, quanto menor a passagem de luz mais opaco e, consequentemente, 


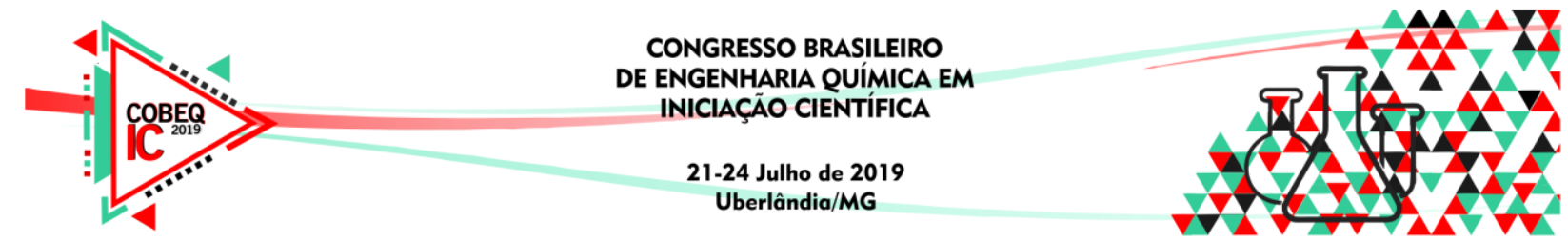

menos transparente o material será. Pela análise da Figura 2, que mostra os resultados para opacidade e transparência, nota-se que as nanofibras de celulose nas formulações C2 e C3 diferenciaram-se dos demais materiais, sendo possível observar que estes reforços aumentaram a transparência dos filmes.

Figura 2 - Opacidade e transparência (obtidos a $600 \mathrm{~nm}$ ) dos materiais biodegradáveis a base de fécula de mandioca (FM), reforçados com nanopartículas de argila (A1, A2, A3) e nanofibras de celulose (C1, C2, C3).
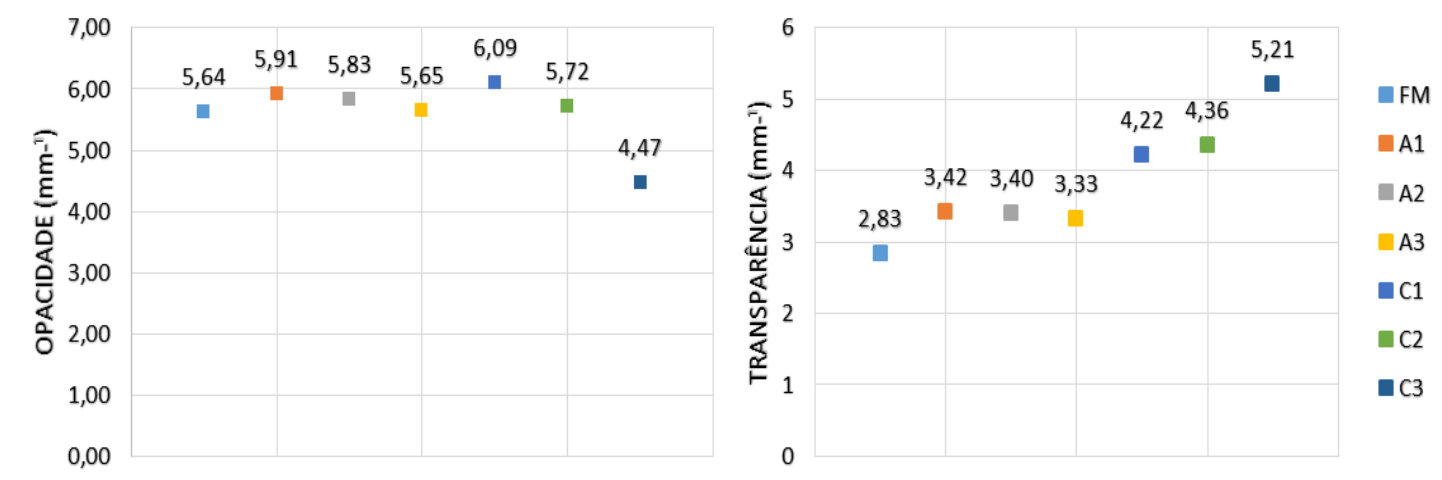

Em relação ao teor de umidade, cujos resultados estão mostrados na Figura 3, não foi possível observar uma variação significativa dos valores, porém percebe-se que a adição dos reforços, tanto as nanopartículas de argila quanto as nanofibras de celulose, levaram a uma tendência de diminuição da umidade. Pode-se então afirmar que, apesar desta característica estar relacionada à presença da fécula de mandioca e sua interação com as moléculas de água da formulação, os reforços alteraram esta relação, interagindo também com a água, levando à diminuição destas moléculas livres, diminuindo a umidade dos materiais.

Figura 3 - Teor de umidade dos materiais biodegradáveis a base de fécula de mandioca (FM), reforçados com nanopartículas de argila (A1, A2, A3) e nanofibras de celulose $(\mathrm{C} 1, \mathrm{C} 2, \mathrm{C} 3)$.

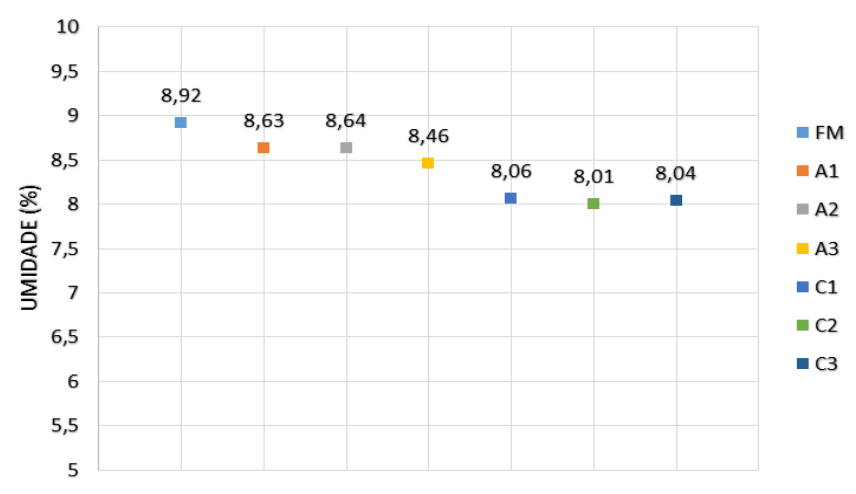

Ao medir a afinidade dos filmes com a água, por meio de suas solubilidades, pretendese estudar uma aplicação futura às embalagens. Visando proteger o produto, o material de embalagem não deve ser muito solúvel. Porém quando a função é de encapsulamento, isto é, revestir um produto que em determinado momento deve ser liberado, então espera-se um material com menor resistência à água (Machado, 2011; Marques, 2018), ou seja, com maior solubilidade. De acordo com os resultados apresentados na Figura 4, percebeu-se que a 


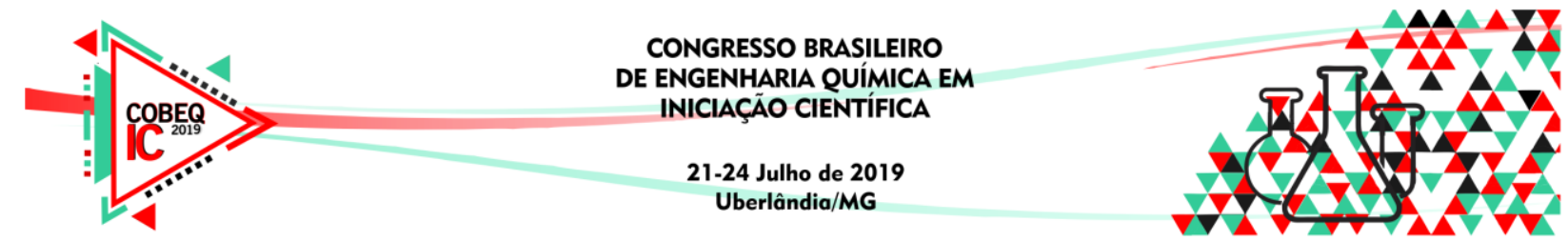

solubilidade dos materiais está mais relacionada com as quantidades de fécula de mandioca e glicerol (Marques, 2018) empregadas nos filmes do que com os reforços selecionados, visto que não houve variação significativa da solubilidade em função do tipo e da quantidade de reforço.

Os dados de grau de intumescimento também são apresentados na Figura 4, e percebese que não houve variação significativa entre as diferentes amostras, o que pode ser explicado pelo fato do grau de intumescimento representar a ligação das moléculas de água com as de amilose e amilopectina presentes na fécula de mandioca (Marques, 2018). Sabendo que esta quantidade não variou nas sete formulações estudadas, esperava-se que não houvesse variação no grau de intumescimento das amostras.

Figura 4 - Solubilidade e grau de intumescimento de umidade dos materiais biodegradáveis a base de fécula de mandioca (FM), reforçados com nanopartículas de argila (A1, A2, A3) e nanofibras de celulose $(\mathrm{C} 1, \mathrm{C} 2, \mathrm{C} 3)$.
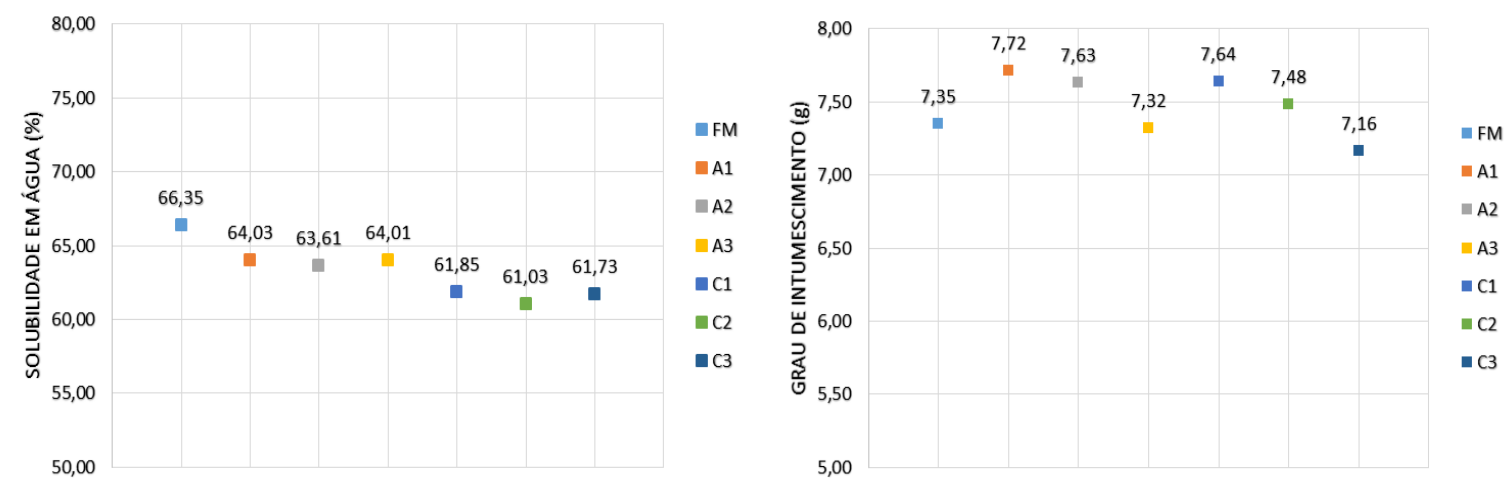

Tratando-se da permeabilidade ao vapor de água, percebe-se pela análise da Figura 5 que a adição de reforços na matriz dos filmes diminui, significativamente, esta propriedade, o que torna interessante a aplicação, tanto das nanopartículas de argila quanto das nanofibras de celulose, uma vez que tais compostos dificultam a troca de água entre o produto embalado e o meio externo à embalagem, retardando o amolecimento ou endurecimento precoce do mesmo.

Figura 5 - Permeabilidade de vapor de água dos materiais biodegradáveis a base de fécula de mandioca (FM), reforçados com nanopartículas de argila (A1, A2, A3) e nanofibras de celulose $(\mathrm{C} 1, \mathrm{C} 2, \mathrm{C} 3)$.

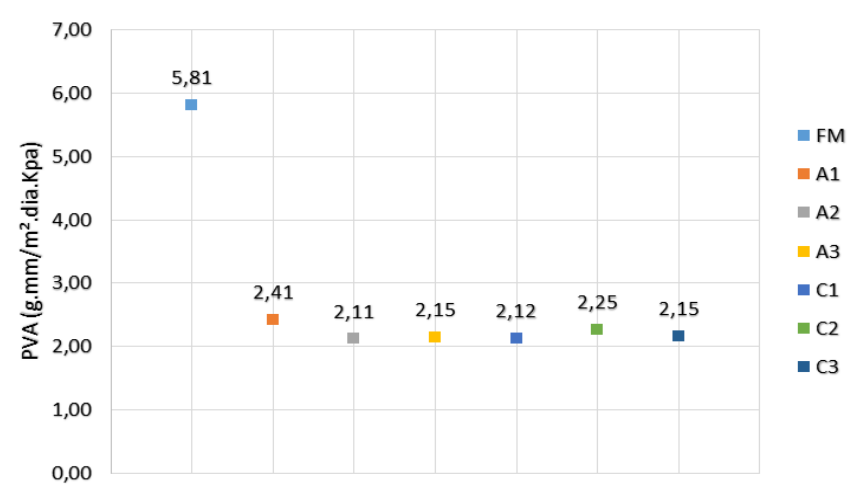




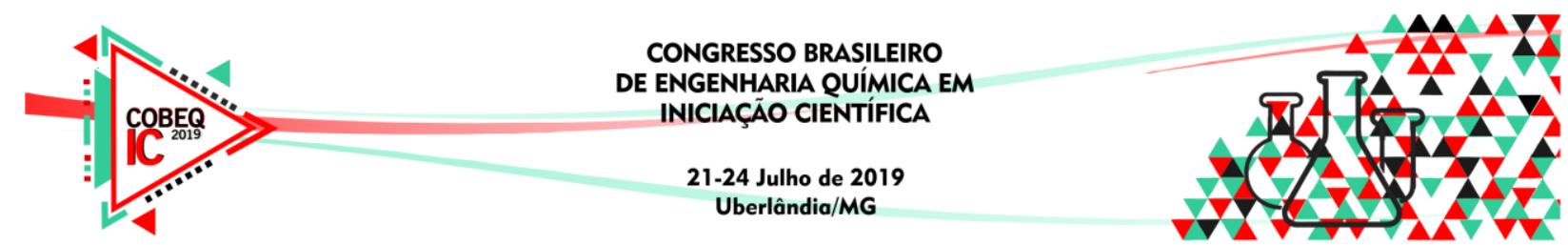

\section{CONCLUSÕES}

Com as análise realizadas é possível perceber a melhoria nas propriedades de barreira e morfológicas dos materiais, justificando a utilização dos reforços, tanto nanopartículas de argila, quanto nanofibras de celulose. Além disso, os materiais apresentaram excelente aparência, sem fissuras, transparentes e pouco opacos, conferindo uma boa apresentação final ao produto.

Portanto, tais resultados e outros que estão sendo obtidos, sugerem o alto potencial da aplicação dos reforços nos materiais a base de fécula de mandioca, que poderão futuramente ser aplicados como embalagens biodegradáveis.

\section{REFERÊNCIAS}

ASTM Standard E 96/E 96M-05. Standard Test Methods for Water Vapor Transmission of Materials, ASTM International, 2005.

ASTM Standard D 882-09. Standard Test Method for Tensile Properties of Thin Plastic Sheeting, ASTM International, 2009.

HENRIQUE, C. M.; CEREDA, M. P.; SARMENTO, S. B. S. Características físicas de filmes biodegradáveis produzidos a partir de amidos modificados de mandioca. Ciênc. Tecnol. Aliment., v. 28, p. 231-240, 2008.

MACHADO, B. A. S. Desenvolvimento e caracterização de filmes flexíveis de amido de mandioca com nanocelulose de coco. Dissertação (Mestrado) - Faculdade de Farmácia da Universidade Federal da Bahia, Salvador, 2011.

MARQUES, G. S. Obtenção de filmes biodegradáveis de amido de mandioca reforçados com nanofibras de celulose de rami. Dissertação (Mestrado) - Universidade Federal do Paraná, Curitiba, 2018.

SOUZA, A. C. Desenvolvimento de embalagem biodegradável ativa a base de fécula de mandioca e agentes antimicrobianos naturais. Tese (Doutorado) - Escola Politécnica da Universidade de São Paulo, São Paulo, 2011. 